DOI: $10.17747 /$ TEDS-2020-17-21

Irina V. Alyoshina

Department of Marketing

State University of Management

Moscow, Russia ialyoshina@gmail.com

\title{
Artificial Intelligence for University Marketing
}

\begin{abstract}
Artificial intelligence (AI) is embedded in digital marketing technologies and so facilitates the development of university marketing management. The article discusses digital globalization trends and factors influential for AI deployment in higher education.

Keywords - artificial intelligence; higher education; digital globalization; marketing; digitalization; platformization
\end{abstract}

\section{ARTIFICIAL INTELLIGENCE FOR THE 21-ST CENTURY}

Artificial Intelligence (AI) can be defined in a wide sense as "the scientific understanding of the mechanisms underlying thought and intelligent behavior and their embodiment in machines." [1]. Accenture regards artificial intelligence as "a constellation of many different technologies working together to enable machines to sense, comprehend, act, and learn with human-like levels of intelligence" [2]. In practice, AI represents software technologies that allow computers and robots to perform some human work faster, more accurately, and in greater volumes. So, accuracy, capacity and speed are often the benefits of $\mathrm{AI}$ in comparison with common human performance. In case of need for large amount of information processing AI saves time, money, space, human and other resources.

AI technologies are basically used for recognition and generation of objects (images, texts, sounds, smells, events and others). AI is an umbrella term for a range of technologies, - data mining, machine learning, natural language processing, neural networks or an algorithm [3].

It is quite difficult today to reveal the sphere of contemporary economy, society and human life unaffected yet with AI technologies. Industrial manufacturing, energetics, transportation, communications, government services, healthcare and social care, education and entertainment are already use some AI decisions. AI is seen as the core technology for an age of digital globalization in the 21-st century [4]. Industry 4.0 and Fourth Industrial revolution restructures the labor markets, eliminating some jobs, changing others and create new professional positions for developers and qualified users of AI technologies.

Universities are also depend on AI development because of their intelligence-intensive activities (teaching, learning, research, management of academic activity) and because of targeting knowledge intensive labor market.

\section{HIGHER EDUCATION DEVEPOPMENT TRENDS}

Sphere of higher education (HE) is currently influenced by a number of interrelated trends:

1. Globalization of markets and resources

2. Massification of higher education

3. Commodization of higher education

4. Democratization of information

5. Digitalization and digital transformation

6. Socialization and Networkization 7. Platformization of business models.

Globalization of markets means growing demand for internationally and globally oriented workforce, able to be employed in international and transnational companies in different countries and regions of the world. Universities compete for the best positions in the world university ratings, for partnerships with global companies and for international students. New technologies conquer global markets and create global demand for specialists ready to work with or on AI systems. 
Massification of $\mathrm{HE}$ is the consequence of technological progress and intellectualization of character of jobs. Mass demand for higher education means more people enter universities in hope to receive better chances for employment after graduation. So more people need to be educated and lifelearning has become a reality. Automation of universities' operations serves the purposes of scaling and cost reduction.

Commodization of HE appeared in parallel with massification of it. If you need to teach large amount of people you have to decide how to do it more easily, how to make complex product available to many people with quite uneven learning abilities. Electronic forms for textbooks, cases, tests and learning software serve the purposes of commodization.

So, MOOC (massive open online courses) appeared as a response to the demand of massification and commodization supported with digitalization trend. The availability of MOOC for global audiences and growing involvement of students in learning value creation have democratized education.

Socialization and networkization of business activity thanks to social media services have expanded social dimension of HE. The majority of students are interconnected through several social networks. Social and networked character of HE was revealed during involuntary transition of universities to distance form of teaching and learning. Universities all over the world used global networking online services - Zoom, Google classroom, Facebook, MS Teams, Skype and others, - for educational, scientific and administrative activities. The leading global techguants use multisided platform business model, connecting different markets with software technologies. Global digital platforms (including learning ones, - Coursera, EdX), - integrate vendors and consumers, supporting global value chains. National, international and global platformization can be seen as perspective dimension for university development. Functioning of global digital platforms depends on AI technologies for big data processing, analytics, customer relationships management, advertising, public relations and marketing.

\section{MARKETING DEVEPOPMENT TRENDS}

Contemporary marketing is seen through holistic approach and is regarded as holistic marketing [5]. American Marketing Association definition sounds as "Marketing is the activity, set of institutions, and processes for creating, communicating, delivering, and exchanging offerings that have value for customers, clients, partners, and society at large [6]".There are four basic dimensions, or components of holistic marketing activity:

1. Integrated (traditional) marketing, - external consumer-, or externally, oriented

2. Internal marketing, targeting employees, or internal audiences of organization as internal consumers

3. Society-oriented, social responsible marketing.

4. Partnership, or relationship, marketing, targeting partners (suppliers of parts and services, helping to create value for customers).

The basic elements of holistic marketing mix as basic components of any marketing decision are $[5]$ :

1. People (consumers, employees, partners, and community/ society)

2. Processes (operations, business-processes)

3. Programs (includes traditional marketing mix: product, price, place, promotion)

4. Performance (marketing, financial, social, technological achievements)

The same business-related trends, noted above are also common for contemporary marketing. Therefore, business practice demonstrates the evidences of:

1. Globalization of marketing activities and operations, targeting (or at least taking in account) international and global markets

2. Massification, commodization and democratization of marketing activities. Some today's marketing technologies (internet marketing and advertising; online survey, or 
questionary, research, social media marketing) are available for small business and individuals, not only for marketing agencies and professionals.

3. Digitalization of marketing is the result of growing internet-access penetration and of technologies' development.

4. Socialization and networkization of marketing we see, using social media services.

5. Platformization of marketing. Platform business models' expansion means the increasing role of marketing on digital platforms, supporting job search, selling goods and services. Multi-sides markets are integrated with platform marketing.

Digitalization of marketing operations is closely interconnected with AI technologies. According to AMA,

"Digital marketing" refers to any marketing methods conducted through electronic devices. This includes online marketing efforts conducted on the internet [7]". The basic methods for conducting digital marketing named there are:

1. Search Engine Optimization (SEO)

2. Search Engine Marketing (SEM)

3. Pay-Per-Click (PPC)

4. Social Media Marketing (SMM)

5. Email Marketing

6. Affiliate Marketing

7. Content Marketing

8. Native Advertising

The majority of these methods depends on AI already integrated in online services (search engines, social media, context advertising). Further digitalization of business processes increases the possibilities for the usage of AI. At the same time IT- infrastructure underdevelopment decreases the chances for digitalization and AI deployment. Anyway, digitalization is common trend, so higher education and universities are supposed to undergo digital transformation, even if involuntarily and from outside if not voluntary and from inside.

\section{ARTIFICIAL INTELLIGENCE , UNIVERSITY AND MARKETING}

The role of AI for university's marketing and management can be presented as intermediation between last two and digital marketing management (Figure 1). Digital marketing to be successful needs large amount of data processing for real-time decision-making. At the same time part of university marketing operations (special events, conferences, discussions, meetings, personal selling) are hold off-line, but anyway are influenced by digital marketing (SMM, SEO, internet advertising, internet public relations, database marketing).

Fig.1. Artificial intelligence and university marketing

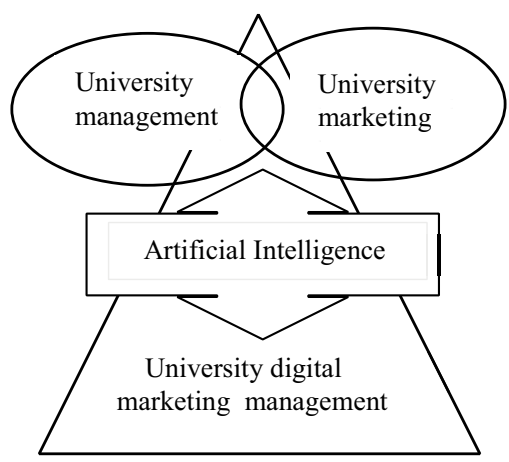


In fact all kinds of university activity, - teaching and learning, scientific research, administrative, - make sense for marketing as soon as they create customer or stakeholders' (students', professors', employees', partners' and society's), experience and so influence university reputation and position at the market of education and research. The basic spheres of AI application for university can be defined as:

1. Institutional and administrative levels (marketing and recruiting, admission and enrollment, curricular and resource planning, administrative and financial student support [3], [8]

2. Teaching and learning (student-facing functions; automatic delivery and teaching course content; diagnosing strengths and automated feedback; curating learning materials; "personalized learning" facilitating collaboration and the teacher's perspective (teacherfacing functions) - [3], [8]

3. Scientific research (automatic systematic academic literature reviews, checking plagiarism and misuse of statistics, flagging unethical behavior [9]. In science, AI technologies reduce the cost of gaining insights and of predictive analysis; find connections, autonomously create hypotheses. AI can deepen understanding of specific spheres of knowledge, facilitate cross-boundaries integration of ideas and crossdiscipline collaboration.

According to holistic marketing approach, all dimensions of AI applications make sense for University marketing, sharing data and information for decision-making.

Positive aspects of using AI in university can be defined as:

1. Effectiveness. AI processes much more information than humans, does it in a real time and with more accuracy. Less mistakes may be done and decisions could be more accurate. This helps to make learning, teaching, guidance, research and institutional decisions more effective.

2. Efficiency. Automation of routine tasks saves costs, efforts and frees up time for creative decisions. Resource pressure becomes more evident for universities because of economic difficulties during pandemic of covid-19.

However, AI is not cure-for-all [10], there are some weaknesses of AI in HE:

1. Narrow character of AI, not general in comparison with human capacity and intelligence. $\mathrm{AI}$ is task-specific and is unable to function in new context or be applied for different type of tasks.

2. The quality of algorithm depends on quality of data collected. Data may be outdated or not new enough. It may be focused on the subset of population not close enough for students (professors, employees) group targeted. In case situation changes, suppose because of covid19, AI doesn't work as previously expected. Algorithm's implicit bias may be a real problem. That is why algorithmic outcome may be disparate. Therefore, people using AI are expected to be knowledgeable enough "to trust or question the algorithmic output [8] ".

3. Huge amount of information is needed for machine learning, dozens of thousands of patterns may need to be collected. So AI may benefit more for large open, or online, universities than for small and medium-size universities.

4. Privacy and data protection may be in question. AI systems sometimes require confidential information. Employees, students and professors may resist providing their personal information (style of learning/teaching, cognitive abilities, health or family situation) for assessment and managerial decision-making.

5. Negative perception of AI by employees if they expect machines could replace them. People need to know how AI impacts their lives.

6. AI could hardly be used without human supervising and control. The society is still not ready yet for driverless education 
In search of digital instruments for increasing competitiveness and reducing cost it is important to keep in mind that "much advanced learning, and its assessment, requires personal and subjective attention that cannot be automated" [9]. So there are still some limitations for automation of intelligence. In order to implement AI technologies [8] for university marketing management one should be prepared to answer the following questions:

1. What functions and roles does the data perform? How it can be used responsibly?

2. What decisions of AI "black box" we do not see? Categorization and visualization of data are the keys for decision making, not only computing.

3. Who is in control of content used by AI? Is it administration, or technology provider, what about students, professors and external audiences?

4. How the outcomes of AI are supposed to be checked for adequacy, effectiveness, context dependence and limitations? How positive and negative outcomes can be measured?

5. What do we loose with datafication? And should and how can we compensate it?

6. What are the priorities for AI implementation? How and whose interests are prioritized?

In an age of digital globalization we can expect the further development of university digital marketing management, that is the expansion of technology in marketing-oriented university management. Digital marketing management today depends on AI. Successful implementation of AI for university marketing demands holistic and inclusive conversation on its fit to university's and higher education's mission.

\section{REFERENCES}

[1] Association for the Advancement of Artificial Intelligence (AAAI.). AI definition. https:// aitopics.org/search

[2] Artificial Intelligence definition.Accenture. https://www.accenture.com/us-en/insights/ artificial-intelligencesummary-index

[3] Zawacki-Richter O., Marín V.I., Bond M., Gouverneur F. Systematic review of research on artificial intelligence applications in higher education - where are the educators? // International Journal of Educational Technology in Higher Education, 28 October, 2019, https://doi.org/10.1186/s41239-019-0171-0

[4] Alyoshina I.V. Artificial Intelligence in an Age of Digital Globalization. /Technologies and Entrepreneurship in Digital Society Proceedings of Intern. Conf TEDS-19, Nov 13, 2019. Saint Petersburg: Real Economy Publishing House, 2019, 68 p., pp. 26-30 https:// managementscience.ru/site/public/elfinder/TEDS2019/TEDS2019-26-30-Alyoshina.pdf DOI: https://doi.org/10.17747/TEDS-2019-26-30

[5] Kotler P., Keller K. Marketing Management.14th Edition. Prentice Hall, 2012, - 816 p.

[6] Definition of Marketing. American Marketing Association. Approved, https://er.educause. edu/articles/2019/8/artificial-intelligence-in-higherJuly 2013 and 2017. Available at: https://www.ama.org/the-definition- education-applications-promise-and-perils-andethical-questions of-marketing/.

[7] What is Digital Marketing. American Marketing Association. Here's how. https:// www.weforum.org/agenda/2017/08/artificialhttps://www.ama.org/pages/what-is-digitalmarketing/ intelligence-will-transform-universities-here-s-how/ 09 Aug 2017.

[8] Zeide E. Artificial Intelligence in Higher Education: Applications,

[9] Dogson M., Gann M. Artificial intelligence will transform universities.

[10] Mims C. AI Isn't Magical and Won't Help You Reopen Your Business. Promise and Perils, and Ethical Questions. August 26, 2019. WSJ, May, 30, 2020. 